\title{
La constitución de una sociedad de economía mixta por parte de una universidad pública
}

\author{
Carlos Frasser ${ }^{1}$
}

\section{RESUMEN}

La constitución de sociedades comerciales con intervención de entidades públicas, lo que en términos jurídicos se conoce con el nombre de sociedades de economía mixta, es un contrato permitido y regulado tanto en el derecho comercial como en el derecho administrativo, a través de disposiciones legales como la Ley 489 de 1998. Sin embargo, existen dudas acerca de la posible intervención de las universidades públicas en este tipo de actos, dada su naturaleza de entes autónomos en virtud de lo dispuesto por el artículo 69 de la Constitución Nacional y la Ley 30 de 1992.

Palabras clave: universidad pública, sociedades de economía mixta, autonomía universitaria, actos de comercio, estructura del Estado, descentralización por servicios.

1 Abogado del Colegio Mayor de Nuestra Señora del Rosario y magíster en Derecho con énfasis en Derecho Administrativo de la Universidad Externado de Colombia. Profesor del Departamento de Derecho Privado de la Universidad del Sinú, Montería, Colombia. Jefe de la Oficina Asesora Jurídica del Municipio de Montería, Colombia; Correo-e: carlosfrasser@yahoo.com Fecha de recepción: 12 de diciembre de 2014. Fecha de modificación: 2 de febrero de 2015. Fecha de aceptación: 3 de abril de 2015. Para citar el artículo: FRASSER, C. (2015). La constitución de una sociedad de economía mixta por parte de una universidad pública. Revista Digital de Derecho Administrativo n. ${ }^{\circ} 13$, Universidad Externado de Colombia, pp. 135-159. DOI: 10.18601/21452946.n13.08 


\title{
The Creation of a Mixed Economy Society on the Part of a Public University
}

\author{
ABSTRACT
}

The creation of commercial societies with public entity involvement, which in legal terms is known as mixed economy societies, is a contract permitted and regulated by both Commercial and Administrative law by way of a legal order, such as Law 489 of 1998 . However, there are doubts about the possible participation of a Public University in these types of acts, due to the nature of autonomous entities according to which is established in article 69 of Colombia's National Constitution and that of Law 30 of 1992.

Keywords: Public University, Mixed Economy Societies, Trade Acts, University Autonomy, Government Structure, Decentralization of Services.

\section{INTRODUCCIÓN}

El presente artículo tiene como pretensión principal decantar la "idea" de la intervención estatal en el mundo de las sociedades comerciales, específicamente a través de una universidad pública, tomando como piedra angular el principio de la autonomía universitaria establecido por el artículo 69 de la Constitución Política colombiana.

En desarrollo de esta idea, se estudiarán conceptos y criterios que en la mayoría de los casos no han sido regulados normativamente, o lo han sido de manera precaria, lo que ha supuesto un sesgo en su aplicación y limitado sus alcances a lo que tradicionalmente ha sido aceptado.

Sobre este particular asunto encontramos un escaso desarrollo normativo y jurisprudencial, quizás producto del espíritu conservador y retrógrado que ha caracterizado al sector académico del país; y así mismo, como consecuencia de la problemática política, social y económica en la que han permanecido inmersas sus universidades públicas durante casi toda su existencia legal.

Estas condiciones han provocado que el desarrollo de los entes autónomos universitarios se haya presentado condicionado por factores externos que han presionado un estancamiento en cuanto a su evolución como actores vivos de la sociedad, en la que actualmente deberían tener una mayor incidencia en relación con las decisiones trascendentales para el país a todo nivel, presentando alternativas y fórmulas de solución a los constantes problemas que reclaman ser resueltos, a fin de coadyuvar en la construcción de un futuro digno del potencial y las capacidades de la nación.

Sin embargo, en medio de las constantes discusiones y conflictos que normalmente se generan al interior de las universidades públicas, con tintes más 
políticos que académicos en la mayoría de los casos, se ha perdido el norte, y se ha producido un aislamiento social respecto del sector de la academia pública, que es percibida por la sociedad en general como generadora de problemas, en vez de ser considerada como fuente de su solución.

En medio de este panorama, plantear la idea de que una universidad estatal celebre un acto jurídico cuyo objeto sea realizar un aporte económico, para que en asocio con particulares lleve a cabo una empresa ${ }^{2}$ en términos eminentemente comerciales, bajo la premisa fundamental del ánimo de lucro, no deja de ser polémico, sobre todo frente a la opinión de puristas y retardatarios que ven en la academia pública un campo propio y excluyente que está vedado para ciertas actividades, especialmente si no encaja en sus fines misionales tradicionales.

Sin embargo, la Constitución Política de 1991 abrió una puerta cuya salida no ha sido suficientemente explorada, al consagrar a favor del sector universitario el principio de autonomía, principio que faculta a los centros de educación superior para autorregularse a través de normas respecto de las cuales no se permite injerencia externa, a la vez que posibilita alternativas de desarrollo innovadoras dentro del marco constitucional (ROBLEDO SILVA, 2010, p. 31 ss.)

Esta gran herramienta, sumada a la tendencia moderna, tanto a nivel legislativo como económico, de involucrar a actores estatales en la comisión de actividades comerciales, antes exclusivas para particulares, abre la discusión sobre el alcance de la denominada autonomía universitaria, y sobre el verdadero papel del sector académico en la vida social.

\section{NATURALEZA JURÍDICA DE LAS SOCIEDADES DE ECONOMÍA MIXTA}

\section{1. Generalidades Del Contrato De sociedad}

Aunque sobre este tema ha existido suficiente ilustración y desarrollo, es necesario plantearlo nuevamente, con el fin de lograr un marco conceptual que nos permita generar una base clara y precisa sobre la cual, después, poder aterrizar en la idea concreta de una sociedad comercial constituida por una universidad pública.

Frente a este asunto, el concepto inicial lo proporciona el artículo 98 del Código de Comercio, que hace parte de su Libro II, dedicado exclusivamente al tema de las sociedades comerciales, y dirigido a regular este acto jurídico de singular importancia desde el punto de vista jurídico, económico y social. 
Se definen las sociedades como un contrato, cuyos elementos esenciales son la pluralidad de personas, el aporte y las utilidades $;$ y que además conlleva la presencia de un elemento subjetivo denominado ánimo de permanecer asociado.

Tan importantes son las sociedades en el mundo actual, que como contrato deberían estar ubicadas en el libro IV del Estatuto Mercantil, el de las obligaciones, donde se encuentra la regulación de los demás contratos mercantiles, pero que, en razón de su relevancia y preponderancia social, cuentan con un libro aparte en el Código de Comercio, destinado exclusivamente a desarrollar una regulación completa de la figura.

La característica que hace especial este contrato frente a los demás, es que es el único que además de ser fuente de obligaciones entre las partes, conlleva el nacimiento de una persona jurídica, es decir, de un ser capaz de adquirir derechos y contraer obligaciones, con independencia de los socios que la conforman. Así lo establece expresamente el segundo inciso del mencionado artículo 98.

Sobre esta idea se pronunció el Maestro José IGNACIO NARVÁEZ de la siguiente manera: "la persona jurídica es un ser distinto de la realidad, que el derecho prefigura como sujeto de derechos patrimoniales; y la capacidad jurídica -atributo esencial y propio del ser humano- la extiende la ley a esos sujetos míticos para facilitar a las asociaciones de individuos el ejercicio de los derechos y el cumplimiento de las obligaciones que se derivan o son inherentes al fin concreto y determinado que aquellas persiguen" (NARVÁEZ, 2002).

La personalidad jurídica otorgada a una sociedad en virtud de la celebración en debida forma del acto jurídico de constitución implica, como regla general, una separación patrimonial entre los socios y la sociedad, que es considerada como la implicación más importante de este contrato, que lo ha convertido en herramienta fundamental dentro del mundo actual de los negocios. Esta personalidad jurídica también conlleva que el nuevo ente esté dotado de los atributos jurídicos de nombre, nacionalidad, capacidad y patrimonio, que son indispensables para que pueda relacionarse autónomamente en su rol de comerciante.

En relación con los elementos esenciales del contrato, es válido realizar algunas necesarias precisiones que sirvan para ilustrar y dar base al desarrollo de la idea que se pretende construir respecto a la participación de una universidad pública en esta clase de actos jurídicos.

Al respecto, la doctrina ha expresado: "Se trata de procurar que la sociedad pueda beneficiarse de cualesquiera bienes susceptibles de ser valorados económicamente. De ahí que no solo quepan las aportaciones apenas dinerarias, sino que se posibilite también la contribución hecha con base en aportes en especie o en industria" (REYES VilLAMiZAR).

En resumen, cuando nos referimos al aporte estamos haciendo referencia a una prestación económica que cada uno de los socios cumple a favor de la sociedad, con el fin de conformar el capital social. 
Una vez cumplido el aporte por los socios reciben a cambio, como contraprestación, un determinado porcentaje de participación en el capital, que recibe el nombre de acciones, cuotas sociales o partes de interés, dependiendo del tipo de sociedad que se haya constituido.

En cuanto a la pluralidad de personas, como elemento esencial del contrato de sociedad, las normas del Código de Comercio la exigen para su celebración como requisito de existencia en cualquiera de sus tipos o formas, es decir, frente a las colectivas, en comandita, las de responsabilidad limitada y las anónimas.

Es bien sabido que desde el año 2008, con la promulgación de la Ley 1258, surgió un nuevo tipo de sociedades denominadas "por acciones simplificadas", conocidas también como SAS, respecto de las cuales, y solo frente a ellas, existe la posibilidad de conformación unipersonal.

No hay mayores restricciones sobre la posibilidad que tiene cualquier persona para celebrar el contrato de sociedad, excepto la contenida en el artículo 103 del Código de Comercio que prohíbe a los incapaces ser socios de sociedades colectivas o gestores en las en comandita ${ }_{i}$ toda persona es libre de participar y obligarse en la celebración de este tipo de actos jurídicos.

Incluso, y como más adelante lo vamos a observar en detalle, los artículos 461 y siguientes del Estatuto Mercantil regulan la presencia del Estado como asociado en estos contratos.

Faltaría indicar que en la utilidad, como el último de los elementos esenciales objetivos del contrato de sociedad, se encuentra implícito el ánimo de lucro en cuanto elemento caracterizador de las sociedades como acto de comercio. No se concibe una sociedad cuyo propósito no sea el de obtener un beneficio económico que luego, bajo reglas predeterminadas, tiene que ser obligatoriamente distribuido entre sus asociados.

En otras palabras, las sociedades son conformadas para llevar a cabo empresas, en los términos del artículo 25 del Código de Comercio, para que al final de cada ejercicio social se produzca un balance económico positivo que redunde en beneficio de sus socios.

Sin esta intención de beneficio económico no existiría razón para que el contrato de sociedad fuera considerado un acto de comercio. Los fines altruistas son ajenos a este tipo de contratos, y más bien son propios de las asociaciones, fundaciones y corporaciones de estirpe netamente civil.

\subsection{DEFINICIÓN Y CONCEPTO DE SOCIEDAD DE ECONOMÍA MIXTA}

\subsubsection{Breve recuento histórico}

Se trata de una figura que ha tenido una prolongada evolución y desarrollo a nivel mundial, y que ha servido a distintos fines de acuerdo con las condiciones y coyunturas históricas del momento. "[E]l expediente de la sociedad de economía mixta surge inicialmente en Bélgica, Suecia y Alemania, con las 
Gemiscbte Wirschaften. En Francia se introduce la figura de la sociedad de economía mixta, mediante su adopción en la Alsacia-Lorena, bajo la legislación alemana, para la gestión de varios servicios públicos, como la distribución de agua, de gas" (TAFur GaLvis, 1984).

En Colombia encontramos las primeras manifestaciones normativas relativas a este tipo de sociedades en el Decreto 1050 de 1955 y la Ley 151 de 1959.

Sin embargo, solo a partir del Decreto 1050 de 1968 se fijó un marco normativo claro y expreso, que permitió determinar sus características y requisitos, así como su verdadera naturaleza jurídica como entidades descentralizadas.

Dentro de las primeras y más importantes sociedades de economía mixta del país encontramos: el Instituto de Fomento Industrial (IFI), el Instituto Nacional de Aprovechamiento de Aguas y Fomento Eléctrico (ICEL), los Fondos Ganaderos, la Empresa Siderúrgica Nacional de Paz del Río, la Empresa Colombiana de Minas (ECOMINAS), entre otras.

\subsubsection{Concepto legal}

El artículo 461 del Código de Comercio indica que son de economía mixta las sociedades comerciales que se constituyen con aportes estatales y de capital privado. Las sociedades de economía mixta se sujetan a las reglas del derecho privado y a la jurisdicción ordinaria, salvo disposición legal en contrario.

De acuerdo con esta definición legal, aparentemente las sociedades de economía mixta solo tendrían como elemento diferenciador, frente a cualquier otra sociedad, el hecho de recibir un aporte cuyo origen es el tesoro público, debiendo en sus demás aspectos seguir las reglas generales dispuestas en el Código.

Sin embargo, la participación estatal en esta clase de figura tiene unas implicaciones de gran importancia jurídica, dado que el hecho de presentarse una inversión de recursos públicos genera una serie de consecuencias fiscales y legales que deben ser necesariamente estudiadas y tenidas en cuenta.

En este sentido surgen aspectos de gran relevancia, como son el régimen de contratación aplicable a sus actos jurídicos, la naturaleza y el régimen legal atinente a sus empleados, las eventuales funciones públicas que podrían desempeñar y la jurisdicción aplicable frente a contingencias o pleitos judiciales, entre otros.

También encontramos la definición legal del artículo 97 de la Ley 489 de 1998, que al tenor literal establece que se trata de "organismos autónomos autorizados por la ley, constituidos bajo la forma de sociedades comerciales con aportes estatales y de capital privado, que desarrollan actividades de naturaleza industrial o comercial conforme a las reglas del derecho privado, salvo las excepciones que consagra la ley".

El tema de la participación estatal en el mundo de las sociedades mercantiles no es nuevo, y ha generado todo tipo de opiniones a favor y en contra, pero en 
últimas ha encontrado suficiente justificación para ser aceptado y desarrollado: "Con el fin de asegurar la producción y la distribución de ciertos productos que considera indispensables para la vida económica de la nación, el Estado invade el campo de las actividades comerciales expropiado a los capitalistas, no solo de sus empresas, sino también de su experiencia y de sus fórmulas, en razón a las estructuras más flexibles del derecho mercantil" (GARRIGUES, 1987).

La doctrina española también ha encontrado razones de peso para justificar la existencia de las alianzas público-privadas para desarrollar empresas, y considerarlas como una herramienta mucho más eficaz que las denominadas nacionalizaciones, o que la creación de empresas meramente públicas: "Pero si las nacionalizaciones -y la clásica 'empresa pública'- han pasado a la historia, no por ello la 'empresa con participación pública' ha dejado de tener una presencia y un papel importantes en las economías nacionales, encontrándose hoy para ella otro tipo de razones, no intelectuales, sino de orden práctico" (ARIÑO ORTIZ, 2008).

En Argentina, por ejemplo, la regulación es mucho más desarrollada, y las justificaciones para que este tipo de sociedades existan son mucho más amplias; es así como, dependiendo del grado de participación estatal, la vocación de permanencia del Estado en la sociedad, el tipo de control societario, y el objeto y finalidad de la empresa, se determinan diferentes formas de existencia de estos entes societarios, tal como lo describe AGUSTín GORDILLO al referirse a las denominadas sociedades del Estado: "La principal diferencia entre las empresas del Estado y las sociedades del Estado es que las segundas adoptan una forma similar a la de las empresas privadas, mientras que las primeras tienen una forma típicamente estatal. A consecuencia de ello, el control del Estado sobre una sociedad del Estado se realiza internamente en la sociedad desde adentro de ella" (GORDILLO).

En Colombia, con la expedición de los decretos 1050 y 3130 de 1968, "la construcción del régimen de organización administrativa de 1968, de manera homóloga al ordenamiento francés, se concibió a una entidad administrativa específica que debería constituirse, cuando quiera que la administración pública fuera a desarrollar actividades de naturaleza industrial y comercial: las empresas industriales y comerciales del Estado" (MONTAÑA PlaTA, 2010).

La existencia de actividades de importancia estratégica para la sociedad, la necesidad de garantizar la prestación de ciertos servicios públicos y la flexibilidad del derecho comercial como marco legal para emprender grandes empresas, han fundamentado el concepto de sociedad de economía mixta. "Ciertamente la sociedad de economía mixta es una de las figuras ideadas para que el Estado actúe, de manera directa en la esfera económica, ya sea con el fin de explotar industrias o actividades de gran envergadura, para generar bienes o servicios, o intervenir en procura de la racionalización y planificación de la economía y el desarrollo económico" (NARVÁEZ GarCía, 2002). 


\subsection{UbiCACiÓn DENTRO DE LA ESTRUCTURA DEL EsTADO}

A partir del artículo 113 de la Constitución Política colombiana encontramos las normas que regulan y construyen la estructura del Estado, partiendo de la base de la tradicional tridivisión del poder público, e incorporando algunos elementos y órganos nuevos destinados a cumplir, en un régimen de autonomía, algunas de las funciones públicas.

De la lectura de los artículos subsiguientes relativos a las diferentes ramas y órganos del poder público, no encontramos ninguno que haga referencia exacta a la ubicación de las sociedades de economía mixta dentro de la estructura del Estado.

Para lograr el propósito de hallar el soporte normativo referente a la ubicación de las sociedades de economía mixta, es preciso aterrizar en la Ley 489 de 1998, por medio de la cual se dictan normas sobre la organización y funcionamiento de las entidades del orden nacional, se expiden las disposiciones, principios y reglas generales para el ejercicio de las atribuciones previstas en los numerales 15 y 16 del artículo 189 de la Constitución Política, y se dictan otras disposiciones.

De conformidad con el artículo $1 .^{\circ}$, la Ley 489 de 1998 tiene como objeto el ejercicio de la función administrativa, determina la estructura y define los principios y reglas básicas de la organización y el funcionamiento de la administración pública.

Algunos autores pretenden solucionar el asunto relativo a la ubicación de las sociedades de economía mixta bajo el entendido de que pertenecen a la rama ejecutiva, y para ello acuden al literal f) del numeral 2 del artículo 38 de la mencionada ley, que define la integración de la rama ejecutiva del poder público en el orden nacional.

Sin embargo, otros juristas ponen en duda esta afirmación, con fundamento en que el artículo 115 de la Constitución Política no incluye a las sociedades de economía mixta, al momento de enlistar a los órganos que integran el poder ejecutivo.

Al respecto ha tenido mayor acogida la primera tesis, siendo la más aceptada a nivel jurisprudencial y doctrinal, ya que al texto del mencionado artículo 38, en interpretación sistemática, se suma lo dispuesto por los artículos 150 numeral 7, 300 numeral 7 y 313 numeral 6 constitucionales.

En consideración a lo anterior, y teniendo en cuenta que se trata de citas que corresponden en todos los casos a la organización e integración de la rama ejecutiva tanto en el nivel nacional como en el territorial, se ha concluido que las sociedades de economía mixta pertenecen a la rama ejecutiva del poder público.

Partiendo de dicha ubicación, la doctrina ha catalogado a estas sociedades dentro del grupo de las entidades descentralizadas por servicios, que en concepto del Maestro VIDAL PERDOMO se deben entender así: "En la descentrali- 
zación por servicios se encuentran esos elementos que son constitutivos de la territorial, como servicios especializados por atender, personalidad jurídica, directores o gestores propios, autonomía para el manejo de los asuntos que le han sido confiados, todo lo cual ha conducido a la admisión de un fenómeno administrativo y jurídico similar" (VIDAL PERDOMO, 1987).

Al respecto, compartimos que el concepto de sociedad de economía mixta corresponda al de una entidad descentralizada por servicios, teniendo en cuenta que sus características son, entre otras, la de tener personería jurídica, autonomía y dirección propias, y el desarrollo de un objeto social específico y concreto, en cuyo desarrollo se convierte en soporte del aparato estatal para el cumplimiento de ciertas tareas y actividades que requieren ser efectuadas bajo reglas especiales.

De otra parte, consideramos que estas sociedades no deben tenerse como exclusivas de la rama ejecutiva del poder público, pues no existe restricción constitucional o legal para que también puedan existir vinculadas a otros órganos públicos, entre otras razones porque a su vez existen regímenes especiales, como el de los entes constitucionales autónomos, cuya reglamentación especial abre diversas posibilidades legales, teniendo en cuenta su posibilidad de autodeterminarse, y la opción de aplicar el derecho privado en los temas correspondientes a la celebración y ejecución de sus contratos.

Esta tesis se fundamenta en el pronunciamiento expreso efectuado por la Corte Constitucional en sentencia C-629 de 2003: "Las sociedades de economía mixta -abstracción hecha del porcentaje de participación estatal en el capital- no forman parte de la rama ejecutiva del poder público. Se conforman a partir de la creación o autorización legal de constitución (para las del orden nacional) o de la autorización para las del orden departamental y municipal, con participación económica, en el correspondiente capital social del Estado y de los particulares" (exp. D-4448, M.P.: Álvaro TAfur Galvis).

La anterior afirmación encuentra mayor respaldo con la aceptación de la existencia de las denominadas sociedades de economía mixta indirectas, o de segundo grado, es decir, aquellas que nacen de la asociación de entidades descentralizadas con particulares, como es el caso en que una sociedad de economía mixta conforma junto con particulares una nueva sociedad, evento para el cual no existe prohibición alguna, y así mismo su vinculación exclusiva a la rama ejecutiva es todavía más discutible.

"La ley 489 de 1998, derogó los decretos 1050 y 3130 de 1968 y el decreto 130 de 1976, que contenían el régimen jurídico de las entidades descentralizadas indirectas o de segundo grado.

No obstante, en relación con las entidades descentralizadas indirectas, la Ley 489 de 1998, recogió parte de la normativa prevista para esta modalidad de entidades en los decretos 3130 de 1968 y 130 de 1976" (YOUNES MORENO, 2014). 


\subsection{MARCO CONSTITUCIONAL Y LEGAL}

\subsubsection{Marco constitucional}

Las sociedades de economía mixta aparecen mencionadas y reguladas en varios artículos de la Constitución de 1991 que ya fueron citados con anterioridad en este trabajo, es decir, los artículos 150 numeral 7, 300 numeral 7 y 313 numeral 6 .

Sin embargo, es pertinente hacer un análisis más profundo del tema con el fin de estudiar aspectos de fondo que nuestra Carta Política plantea, sobre asuntos económicos y sociales que tienen gran importancia al momento de examinar la figura de las sociedades de economía mixta, ya que si revisamos los textos arriba señalados, nos encontramos con una regulación dirigida a la forma y no a lo verdaderamente sustancial.

En este sentido, es pertinente citar el Preámbulo de la Carta Política, que establece como finalidad "asegurar a sus integrantes la vida, la convivencia, el trabajo, la justicia, la igualdad, el conocimiento, la libertad y la paz". Nótese que se trata del establecimiento de principios-fin, que se deben tener en cuenta como ejes rectores de toda interpretación y aplicación de la ley.

Después del Preámbulo constitucional encontramos el artículo 2. que prevé como fin esencial del Estado "promover la prosperidad general"; y así mismo el artículo 38 mediante el cual "[s]e garantiza el derecho de libre asociación para el desarrollo de las distintas actividades que las personas realizan en sociedad".

Bajo los principios fundamentales arriba citados nos remitimos al Título XII, "Del régimen económico y de la hacienda pública", en el que encontramos normas como el artículo 333, que describe la "empresa como base del desarrollo", y el artículo 334, que prevé la intervención del Estado, "por mandato de la ley, en la explotación de los recursos naturales, en el uso del suelo, en la producción, distribución, utilización y consumo de los bienes y en los servicios públicos y privados".

Una síntesis de este planteamiento la encontramos expresada magistralmente por la doctrina bajo la denominación de "principio del orden económico y social justo": la "presencia del Estado en todos los aspectos estelares de su vida: así sea interviniendo directamente en los fenómenos económicos, políticos, culturales y de otros géneros que puedan verse afectados, creando las condiciones para que la misma sociedad sea la que lleve la iniciativa en ese equilibrio de convivencia que se espera" (SAnTOFImiO GAMBOA, 2003).

De lo anterior concluimos la gran importancia que le otorga la Constitución a la figura de la empresa, entendida en los términos del artículo 25 del Código de Comercio como toda actividad económica dirigida a producir, transformar, circular, custodiar bienes o a la prestación de un servicio.

"Toda empresa industrial o comercial requiere ante todo libertad. Y después, un poder ordenador, una mente creadora y una autoridad capaz de integrar 
y ajustar los distintos elementos que la integran con rapidez, sin sujeción a normas rígidas" (ARIÑO ORTIZ, 2008).

Se trata de un asunto eminentemente económico, pero que por mandato de la Constitución debe estar encaminado al desarrollo social y a la creación de riqueza, por lo tanto, se justifica la intervención estatal para garantizar el cumplimiento del fin esencial de lograr la prosperidad social.

Esta intervención estatal no solamente está prevista bajo las formas tradicionales, como la regulación, el control y la vigilancia, sino que también se concibe con la participación de los entes estatales como sujetos activos y partícipes de las empresas, emprendiendo la comisión de asuntos comerciales que permitan la prestación de ciertos servicios y la producción y comercialización de bienes a través del Estado empresario.

Una de las formas más comunes de realizar este tipo de intervención es a través de las sociedades de economía mixta.

\subsubsection{Marco legal}

Desde el punto de vista legal, las sociedades de economía mixta se deben examinar en dos perspectivas, la primera de ellas es la que nos ofrece el derecho privado, específicamente el derecho mercantil i la segunda es la que encontramos en las normas del derecho público, más precisamente, las consagradas en el derecho administrativo.

a) En lo que respecta al derecho comercial, debemos atenernos a lo establecido por los artículos $461 \mathrm{y}$ siguientes del Estatuto Mercantil, que como se dijo anteriormente, las define de la siguiente manera: "Son de economía mixta las sociedades comerciales que se constituyen con aportes estatales y de capital privado".

Seguidamente el artículo 462 ibídem regula aspectos atinentes al acto de constitución de este tipo de sociedades, e indica como requisito previo la existencia de "disposición que autorice su creación".

También es pertinente señalar que, de conformidad con los artículos 461 y 468, el régimen aplicable a las sociedades de economía mixta, por regla general, es el establecido por las normas de derecho privado, es decir, las del Libro II del Código de Comercio; y que la jurisdicción competente para resolver sus litigios es la ordinaria.

Con lo anterior se reafirma el carácter de comerciante que adquieren estas sociedades, y la igualdad de condiciones a que se somete el Estado cuando participa de ellas, perdiendo su habitual condición de parte preponderante en las relaciones jurídicas en las que interviene, dentro de las que generalmente detenta el poder a través de cláusulas exorbitantes o de la posibilidad de aplicar la caducidad o imponer multas contractuales. 
b) De otra parte, el derecho administrativo también se encargó de regular algunos aspectos de las sociedades de economía mixta, principalmente a través de ciertas normas establecidas por la Ley 489 de 1998.

Tal como se indicó anteriormente, por medio de la Ley 489 de 1998 se establecieron reglas sobre la organización y funcionamiento de las entidades del orden nacional, se expidieron las disposiciones, principios y reglas generales para el ejercicio de las atribuciones previstas en los numerales 15 y 16 del artículo 189 de la Constitución Política, y se dictaron otras disposiciones.

Respecto del tema de las sociedades de economía mixta, el mencionado precepto legal, a través de su artículo 97, antes transcrito, establece una definición de las mismas, y efectuaba una precisión respecto al porcentaje mínimo de participación social que debía ostentar el Estado, para que efectivamente dicha sociedad adquiriera la naturaleza de "economía mixta".

Bajo esta norma, y para los efectos de configurar la naturaleza jurídica del ente societario arriba señalada, la participación estatal no podía ser inferior al $50 \%$ del total del capital suscrito y pagado.

La norma en mención fue declarada inexequible por la Corte Constitucional, por medio de la sentencia C-953 de 1999, con ponencia del magistrado Alfredo Beltrán SierRA, argumentando que la Constitución Nacional no estableció un porcentaje mínimo de participación estatal en el capital social para la configuración de una sociedad como de economía mixta.

En virtud del mencionado pronunciamiento de la Corte, toda sociedad en la que el Estado tenga participación social, llámense acciones, partes de interés o cuotas sociales, adquiere la condición de economía mixta, sin importar si dicho porcentaje sobrepasa o no el $50 \%$ del total de su capital.

La Corte, en la sentencia en mención, no modificó el artículo 97 de la Ley 489 de 1998 en lo atinente al tratamiento de empresa industrial y comercial del Estado, frente a aquellas sociedades de economía mixta cuya participación estatal supere el $90 \%$ del capital social, y por lo tanto, en ese caso, dichas sociedades quedaría sometidas a lo dispuesto por la misma Ley 489 en sus artículos 85 a 94 .

Otra disposición legal que es preciso citar como norma de derecho público aplicable a las sociedades de economía mixta es la Ley 80 de 1993, también denominada Estatuto de Contratación Pública, ya que bajo sus reglas se definen los casos en los cuales estas sociedades se deben acoger a sus procedimientos en las fases precontractuales, de ejecución de contratos y poscontractuales; $\mathrm{y}_{\text {, }}$ contrario sensu, los eventos en los que las reglas de contratación aplicables son las del derecho privado.

El criterio diferenciador no es otro que el de la participación social estatal superior al 50\% del capital, caso en el cual evidentemente se tendrán que cumplir los requisitos dispuestos para la contratación pública, cuya regla general implica la realización de licitaciones o concursos al momento de elegir al contratista. 
Sin embargo, para el desarrollo de las actividades comerciales e industriales descritas en el objeto de la sociedad, el literal m) del numeral 1 del artículo 24 de la Ley 80 de 1993 dispone la posibilidad de utilizar el mecanismo de la contratación directa, con el fin de hacer competitiva a la empresa frente a sus eventuales competidores privados.

Por último, el Decreto 661 de 2002 dispone el régimen salarial de los empleados públicos pertenecientes a sociedades de economía mixta sometidas al régimen de las empresas industriales y comerciales del Estado.

\subsection{FORMAS QUE PUEDEN ADOPTAR}

Dentro del panorama normativo colombiano existen, en la actualidad, seis verdaderos tipos sociales, es decir, especies de sociedades que gozan de características propias que las hacen diferentes entre sí, y que además cuentan con reglas específicas que las regulan de manera particular en cada uno de los casos.

Cinco de ellas las encontramos establecidas en el Decreto 410 de 1971, dentro del cual se permite que los usuarios de sus normas puedan escoger libremente entre las sociedades colectivas, las en comandita simple y por acciones, las de responsabilidad limitada y las anónimas.

Posteriormente, con la expedición de la Ley 1258 de 2008 surge la posibilidad de constituir una nueva clase de sociedad denominada por acciones simplificada, conocida por su sigla como SAS.

Respecto de las sociedades de economía mixta se encuentra supremamente decantado el concepto de que ellas no constituyen un tipo social distinto de los que se indicaron anteriormente, sino que, eligiendo uno de ellos, cualquiera que sea, se tiene la posibilidad de constituir una persona jurídica cuyo capital social se halle conformado con aportes públicos y aportes privados, rasgo que la caracterizaría como mixta, pero siempre bajo el entendido de estar utilizando uno de los tipos sociales legalmente establecidos.

Incluso, la Superintendencia de Sociedades ha sido clara en aceptar la existencia de sociedades de economía mixta bajo cualquiera de las formas sociales existentes, incluida la SAS, tal como quedó expresado en el siguiente texto: "En otros términos, las sociedades de economía mixta [...] pueden constituirse bajo cualquiera de las formas de sociedad prevista en el Código de Comercio colectiva, en comanditas simples o por acciones, de responsabilidad limitada, anónima o simplificada por acciones, toda vez que la ley colombiana no señala ninguna en especial" (Superintendencia de Sociedades, Oficio 220-024523 de 23 de abril de 2012). 


\section{PROCEDIMIENTO Y REQUISITOS PARA LA CONSTITUCIÓN DE UNA SOCIEDAD DE ECONOMÍA MIXTA}

\subsection{REQUiSITOS LEGALES PARA SU CONSTITUCIÓN}

La constitución de una sociedad de economía mixta es un procedimiento complejo, ya que las normas que regulan la materia disponen el agotamiento de dos actos jurídicos indispensables para dar nacimiento al nuevo ente moral, efecto para el cual confluyen y se entrelazan disposiciones normativas de derecho público con las de derecho privado.

Los artículos 49, 50 y 98 de la Ley 489 de 1998, así como el artículo 462 del Código de Comercio, coinciden en exigir, como requisitos para la creación de una sociedad de economía mixta, por un lado, la existencia de un acto estatal por medio del cual se disponga su creación o esta sea autorizada; y de otra parte, la celebración de un contrato de sociedad comercial en los términos del artículo 110 del Código de Comercio.

En la actualidad también puede tenerse, como marco normativo para el contrato o el acto jurídico unilateral de creación, el dispuesto para la constitución de SAS que establece la Ley 1258 de 2008.

\subsubsection{La autorización legal para su constitución}

Dentro del procedimiento para la constitución de una sociedad de economía mixta es preciso contar con un acto estatal por medio del cual se obtenga una autorización o facultad que le permita a una determinada entidad de derecho público celebrar válidamente el contrato de sociedad comercial.

\footnotetext{
"Al igual que respecto de los establecimientos públicos y de las empresas industriales y comerciales, en nuestro régimen jurídico se encuentra la previsión de que la creación de las sociedades de economía mixta está sujeta a la voluntad legal. Sólo mediante ley o acto a ella equivalente puede darse a la vida jurídica una sociedad de este tipo" (TAFUR GALviS, 1984).
}

Esta autorización, que muchos doctrinantes denominan "ley de autorización", en la realidad no encaja dentro de la definición estricta de lo que tradicionalmente se define como ley en sentido material.

Sea por su contenido singular y concreto, o por su origen en asambleas departamentales y concejos municipales en ciertos casos, su naturaleza es completamente distinta a lo que en derecho corresponde a un precepto legal en sentido material, y solo en algunos casos podría tenerse como ley en sentido formal.

En efecto, en palabras de Pérez EsCOBAR, "[d]esde el punto de vista material se entiende por función legislativa la actividad del Estado encaminada a dictar 
reglas de derecho o leyes en sentido material, o sea normas de conducta social que son obligatorias, generales y permanentes. Estas leyes son las que forman el derecho escrito" (PÉREZ ESCOBAR, 1997).

En consideración a lo anterior, podemos concluir que la autorización estatal para constituir sociedades de economía mixta no corresponde a la definición de ley en sentido material, entre otras razones porque el contenido de dicho acto debe ser singular y concreto, y de ningún modo podría tratarse de una facultad general e indefinida.

De conformidad con el artículo 50 de la Ley 489 de 1998, el contenido de la autorización debe ser el siguiente: "Contenido de los actos de creación. La ley que disponga la creación de un organismo o entidad administrativa deberá determinar sus objetivos y estructura orgánica, así mismo determinará el soporte presupuestal de conformidad con los lineamientos fiscales del Ministerio de Hacienda y Crédito Público".

Adicional a lo anterior, cuando se trate de sociedades de economía mixta distintas a las del orden nacional, el acto estatal de creación en la mayoría de los casos los expiden las asambleas departamentales y concejos municipales, siendo entonces mucho más claro que no se trata de leyes sino de actos administrativos expedidos por dichas corporaciones públicas, que en todo caso deberán contener los mismos elementos dispuestos por el artículo 50 de la Ley 489 de 1998.

\subsubsection{La celebración de un contrato de sociedad mercantil o el acto unilateral de constitución}

Desde el punto de vista procedimental, una vez recibida la autorización legal para la creación de la sociedad de economía mixta a favor de una determinada entidad pública, se deberá proceder por parte de su representante legal a la celebración de un negocio jurídico de estirpe netamente mercantil, tal como lo es el contrato de sociedad comercial regulado en el libro II del Código de Comercio; o el acto jurídico contractual o unilateral dispuesto por la Ley 1258 de 2008, en el evento en que se elija la conformación de una sociedad por acciones simplificada.

En cualquiera de los casos, se trata de un negocio jurídico cuya principal característica es el ánimo de lucro, es decir, conlleva la entrada del Estado en la realización de empresas de naturaleza mercantil, que en principio se tienen como extrañas a las ocupaciones normales de un ente público, pero como ya se dijo anteriormente, encuentran justificación por razones diversas, siempre inspiradas en alcanzar o preservar un bien jurídico de mayor importancia para la comunidad en general, y no en la mera expectativa de generar una utilidad o dividendo a su favor.

Si se opta por constituir uno de los tipos de sociedad que dispone el Código de Comercio, se tratará de un contrato, en el que la pluralidad de personas será 
requisito esencial, y bajo cuyas normas se podrá escoger como posibilidades de tipificación entre la sociedad colectiva, la en comandita simple o por acciones, la de responsabilidad limitada o la sociedad anónima. En uno u otro caso, el trámite implicará pactar con los futuros socios el clausulado obligatorio que dispone el artículo 110 del Estatuto Mercantil, y cumplir con la solemnidad de elevarlo a escritura pública, para después ser registrado en la cámara de comercio del lugar donde la sociedad tendrá su domicilio principal.

$\mathrm{Si}$, por el contrario, se elige la conformación de una sociedad por acciones simplificada, se tendrán que seguir las reglas dispuestas por la Ley 1258 de 2008, contando con la opción de celebrar el acto de constitución de manera unilateral, y así mismo, sin la obligación de acudir a una notaría para el trámite de la escritura, ya que el mero documento privado con reconocimiento de firmas bastará, culminando el trámite con la respectiva matrícula en el registro mercantil.

\subsection{SUJETOS QUE PUEDEN INTERVENIR EN LA CONSTITUCIÓN}

Tal como su nombre lo indica, uno de los propósitos principales de una sociedad de economía mixta es el de conjugar capital público y capital privado para realizar actividades de tipo industrial o comercial. En este orden de ideas, la presencia del Estado es imprescindible para que una determinada sociedad pueda ser considerada como de naturaleza mixta.

Bajo este entendido, la Ley 489 de 1998 estableció normas para la constitución de sociedades público-privadas del nivel nacional que pertenezcan a la rama ejecutiva del poder público, que a nuestro entender son muy importantes y obligatorias para las entidades y organismos que hagan parte de dicho sector, pero que de ninguna manera pueden interpretarse como restrictivas o limitantes para que entidades de naturaleza y orden distinto puedan emprender este tipo de empresas.

En este sentido, la Ley 489 de 1998 sienta las bases legales para que las personas jurídicas de derecho público que conforman la rama ejecutiva en el nivel nacional puedan constituir sociedades comerciales al asociarse con particulares, y también hace referencias para que dicha asociación pueda presentarse en el nivel territorial, específicamente tratándose de municipios y gobernaciones, a los que hace directa alusión.

El artículo 38 de la mencionada ley dispone la integración de la rama ejecutiva en el orden nacional, clasificando su composición en el nivel central y descentralizado por servicios, y posteriormente en sus artículos 46 y 97 faculta a las entidades públicas que la componen, como los ministerios, departamentos administrativos, establecimientos públicos y demás, así como a las entidades territoriales, para constituir y ser asociadas en sociedades de economía mixta.

Ahora bien, no existe prohibición legal o constitucional para que un organismo distinto a los de la rama ejecutiva pueda también participar en la ce- 
lebración de este tipo de negocio jurídico, siempre y cuando sea compatible con su naturaleza y carácter.

Precisamente el presente escrito va encaminado a demostrar que una universidad pública puede perfectamente hacerlo, así como también lo podrían hacer otros entes autónomos de carácter constitucional como el Banco de la República o las corporaciones autónomas regionales.

En resumen, cualquier entidad estatal que cumpla función administrativa, y que para la consecución de sus fines requiera descentralizar alguno o algunos de sus servicios, previo el cumplimiento de los requisitos establecidos legalmente, podrá constituir una sociedad de economía mixta.

En la actualidad, la función administrativa no es una competencia exclusiva de las administraciones públicas, opinión en la que coinciden múltiples voces, tal como lo expresa MONTAÑA PLATA de manera concreta y precisa: "así mismo, es común encontrar entes autónomos y/o de control que sin pertenecer a los tres poderes públicos convencionales desarrollan actividades relacionadas con el concepto de función administrativa aludido, y finalmente, cada vez es menos extraño percibir particulares que legítimamente cumplen funciones administrativas" (MONTAÑa Plata, 2010).

\subsection{LA SOCIEDAD DE ECONOMÍA MIXTA}

La sociedad de economía mixta hace parte de la administración y es una expresión del concepto de descentralización por servicios: "Son entidades descentralizadas aquellas que, integradas al Estado, actúan, respecto de los órganos administrativos centrales, con autonomía en la prestación de un servicio público o el ejercicio de una función administrativa, estando sujetas a un especial control por parte de aquellos órganos" (TAFur GaLviS, 1984).

Tal como se evidenció anteriormente, según sus fundamentos y naturaleza jurídica, las sociedades de economía mixta corresponden al desarrollo de la figura de la descentralización por servicios, es decir, existen y se justifican, en palabras del Maestro VIDAL PERDOMO, "cuando se considera conveniente desprender de ese conjunto alguno o algunos para confiárselos a una entidad nueva que se crea al efecto. El nombre más frecuentemente empleado es el de instituto, pero a veces el organismo se designa corporación, servicio, empresa, según el asunto que atienda" (Vidal PeRdOMO, 1987).

Este tipo de descentralización corresponde al desarrollo de algunos principios de la función administrativa, en especial a los de eficacia, economía y coordinación (BREWER-CARÍAS, 2005, p. 127).

En efecto, el cumplimiento de los fines esenciales del Estado, y la consecución de los intereses generales, se deben lograr bajo los principios señalados por el artículo 209 de la Constitución Nacional, y en especial, la descentralización administrativa corresponde a los siguientes: eficacia, economía y coordinación. 
La descentralización por servicios ha resultado mucho más dinámica y efectiva que la descentralización territorial, ya que aunque la Constitución de 1991 estableció las bases y fundamentos para lograr el fortalecimiento de la organización departamental y municipal, el traslado de funciones del nivel central a las entidades territoriales no se puede considerar exitoso, el manejo de los recursos no ha sido el adecuado, y sobre todo, la planeación y las técnicas de administración aplicadas por los gobiernos locales han carecido de rigor y pulcritud en la generalidad de los casos.

En este sentido cobran vigencia las afirmaciones hechas a nivel doctrinal en 1987 sobre el porvenir de la descentralización administrativa:

"La descentralización por servicios se amplía cada vez más como técnica administrativa de atención de ciertas necesidades que se quieren sustraer de la influencia política que pesa sobre la administración estatal, hasta el punto que algunos critican con acerbidad la proliferación de establecimientos públicos y de otras formas administrativas que envuelven el mismo fenómeno de descentralización" (Vidal Perdomo, 1987).

Bajo la premisa de que las sociedades de economía mixta son entidades descentralizadas por servicios, debe quedar claro entonces que hacen parte de la administración, y que guardan una relación de vinculación con el ente público que las constituye.

En este sentido, estas sociedades tienen una relación directa con el Estado, que es de menor entidad que la que de las entidades adscritas, pero del que de igual forma emana un control de tutela, es decir, un poder de orientación que implica un control de su actividad para que se pueda lograr una integración armónica con los demás organismos estatales.

\section{INTERVENCIÓN DE UNA UNIVERSIDAD PÚBLICA EN ACTIVIDADES COMERCIALES}

\subsection{FINES MISIONALES DE LA UNIVERSIDAD PÚBLICA}

La misión de una universidad puede corresponder a distintos propósitos, dependiendo de su naturaleza pública o privada. En el caso de una universidad pública, ella se enmarca en el cumplimiento de las obligaciones del Estado en materia de generar condiciones de desarrollo y bienestar al conjunto de la sociedad.

La función social de una universidad pública es la generación de desarrollo en lo cultural, en lo económico, en lo político, en lo social y en lo ambiental, en el contexto en el cual se desenvuelve.

Esta responsabilidad social de las instituciones universitarias públicas en materia de desarrollo se materializa en la generación de conocimiento apropiado, 
formación integral de personas e incorporación del conocimiento apropiado a las distintas actividades y haceres de la sociedad en su conjunto.

Es claro que cada contexto tiene sus propias características y dinámicas en cada una de estas dimensiones. Por tanto la forma como una universidad pública responda a los requerimientos de desarrollo del contexto en el cual se desenvuelve dependerá del conocimiento y conciencia que tenga de los problemas que afectan el bienestar de las personas que habitan en su contexto.

La tradicional visión de los fines misionales: docencia, investigación y extensión, ha de renovarse para ser entendida de manera sistémica, de tal manera que entre los tres se genere una sinergia que permita el desarrollo del ente universitario como real aportante a la solución de los problemas de su entorno.

La visión de la acción universitaria como sistema permite ver, establecer o comprender los flujos de asuntos que conectan los tres elementos constituyentes de los procesos misionales de la universidad. Los flujos de interrelación se pueden sintetizar así:

- La investigación le aporta a la docencia conocimiento apropiado.

- La docencia le aporta a la extensión actualización a través de la educación continua.

- La docencia le aporta a la investigación interrogantes.

- La extensión le aporta a la investigación problemas que deben ser resueltos a través de la investigación.

- La investigación debe no solo resolver los problemas, sino convertir sus soluciones en tecnología, la cual debe, a su vez, ser transferida al contexto a través de la extensión. Solo en esta medida la investigación será pertinente y socialmente útil.

- La extensión aporta a la docencia pertinencia, y solo se es pertinente en la medida en que el conocimiento y las competencias transferidas o generadas sean las requeridas por el contexto.

\subsection{LA AUTONOMÍA UNIVERSITARIA}

La autonomía de la universidad es uno de los principios más valiosos que el constituyente de 1991 incorporó en el texto constitucional y posteriormente el legislador en los artículos 28 y siguientes de la Ley 30 de 1992. Es indudablemente de importancia esta garantía para el cabal cumplimiento de su misión; difícil sería llevar a cabo el proceso de formación de las personas en un ambiente enrarecido por presiones para que este se lleve a cabo con determinados enfoques o posturas políticas, económicas o filosóficas, o designar a las autoridades universitarias para favorecer intereses particulares. Estas dificultades en ocasiones se han resuelto a favor de la libertad de cátedra, enseñanza y aprendizaje, y la autodeterminación. Atrás han quedado, como episodios tristes, las épocas en que ciertas instituciones o poderes imponían 
a las instituciones educativas sus directivas, determinados textos, métodos de enseñanza, enfoques científicos y filosóficos.

Para romper con esa tradición de injerencia en la vida de las universidades, se consagró la potestad especial relativa al principio de autonomía universitaria en el artículo 69 de la Constitución Política, en los siguientes términos: "Se garantiza la autonomía universitaria. Las universidades podrán darse sus directivas y regirse por sus propios estatutos, de acuerdo con la ley".

La autonomía universitaria se erige entonces como la facultad que tienen las instituciones de educación superior para autodeterminarse y autorregularse de conformidad con la visión y misión que quieran desarrollar en el marco del Estado social de derecho y en total concordancia con la estructura del Estado consagrada en el artículo 113 de la Constitución Política.

De lo anterior se resalta que el ejercicio de la autonomía universitaria debe darse en el marco del Estado social de derecho y de la ley, y en concordancia con la estructura del Estado. En consecuencia, a pesar de su naturaleza constitucional y de su importancia en el Estado social de derecho, esta autonomía no es absoluta, tiene límites, por lo tanto, no es dable predicar un carácter absoluto de ella. Pero además, es una forma de protección a una actividad de gran valía para la sociedad como es la formación de ciudadanos y de profesionales, no un derecho subjetivo.

Como se había anotado, con la garantía de este principio se busca que las universidades puedan cumplir no solo la misión y objetivos consagrados por la ley, en especial contribuir al desarrollo social, económico y del conocimiento:

"La universidad, cuyo fundamento es el perfeccionamiento de la vida y cuyo objetivo es contribuir a la formación de individuos que reivindiquen y promuevan ese fundamento, a través del dominio de 'un saber' y de la capacidad de generar conocimiento, reclamando su condición de fines en sí mismos y no de meros instrumentos, es la universidad que requiere, para 'ser', del reconocimiento efectivo de su autonomía" (Corte Constitucional, sentencia C-220 de 1997, M.P.: FABIO MORÓN DÍAZ).

De lo anterior se puede colegir que la autonomía universitaria está inspirada en una filosofía jurídica, que tiene dos campos de acción que permiten la realización material de sus acciones pedagógicas y de formación: el primero tiene que ver con la autorregulación filosófica que funciona en el contexto de libertad de pensamiento y pluralismo ideológico que debe garantizar la universidad para llevar a cabo el proceso de educación, y el segundo está relacionado con la autodeterminación administrativa, es decir, la facultad que tienen estos centros educativos para darse su propio gobierno y elegir sus autoridades.

En estos dos campos precitados, la participación de la comunidad universitaria es de la esencia de su autonomía; se necesita por tanto, en desarrollo de este principio, que se garantice de manera real y efectiva que los miembros 
de la comunidad universitaria puedan expresarse sobre todos los aspectos de orden académico y administrativo, pues actuar en sentido contrario desvirtuaría la autonomía universitaria en, autonomía de las directivas administrativas y académicas, además de oponerse a principios democráticos como el de la democracia participativa; así lo ha señalado en una extensa línea jurisprudencial la Corte Constitucional.

Ha dicho en ese sentido la Corte que la autonomía implica establecer "mecanismos internos que les permitan expresarse sobre todos los asuntos que interesan a la vida académica y administrativa de la universidad, así como la posibilidad de participar efectivamente en las decisiones correspondientes. Se abandona pues un criterio autoritario en la universidad para dar cabida de manera concreta al principio de la democracia participativa en los claustros" (Corte Constitucional, sentencia C-829 de 2002, M.P.: Alfredo Beltrán SIERRA).

No resulta entonces extraña la participación de la comunidad en las decisiones que afectan sustancialmente la vida universitaria, como la designación de los rectores y de los representantes ante los órganos de representación, mediante ella se ejerce un control al poder de los consejos superiores, y se abandona de esta manera un criterio autoritario en la universidad.

Si la universidad es garantista, reconoce los derechos de la comunidad universitaria, de sus integrantes, entonces se ha instituido el poder (Consejo Superior, Rector, decanos, jefes de departamentos) por medio de la participación, es decir, a través del voto; pero si este poder no actúa para favorecer los intereses de la institución, sino los suyos propios, o se cambian las reglas establecidas dentro del ordenamiento universitario con fines particulares, podemos preguntarnos si esa universidad es democrática, fomenta la convivencia, la tolerancia y la paz, si es un ejercicio auténtico de autonomía universitaria, y la respuesta seguramente será contundente: no. En este sentido, la autonomía universitaria no es solo un asunto de meras facultades, tiene un núcleo esencial formado por varios tópicos, ya señalados con anterioridad, que apuntan finalísticamente a la defensa de un bien y un servicio público, pero en esencia de un derecho: la educación.

\section{CONCLUSIÓN}

De conformidad con los diferentes argumentos de tipo legal, doctrinal y jurisprudencial antes citados, existe suficiente soporte para poder afirmar que dentro del marco normativo vigente en Colombia, sería perfectamente legal la constitución de una sociedad de economía mixta por parte de una universidad pública.

La anterior afirmación se fundamenta específicamente en los pilares que a continuación se exponen: 
- La autonomía universitaria: tal como quedó expuesto anteriormente, consiste en la capacidad de autodeterminación con la que dota la Constitución Política colombiana a los entes universitarios, y que los faculta para tomar sus propias decisiones sin injerencias externas

Una de las mayores expresiones de esta facultad de autodeterminarse se encuentra materializada en los estatutos que las universidades se dictan a través de sus órganos de decisión, y que sirven como normas de conducta de obligatorio cumplimiento para los distintos actores académico-administrativos que las integran.

Del examen de la generalidad de los estatutos generales de las universidades colombianas, en desarrollo de las facultades del artículo 69 de la Constitución Política y los postulados de la Ley 30 de 1992, encontramos un sinnúmero de expresiones de esta autonomía, pero en especial, en lo que respecta al tema de este artículo, la posibilidad de constituir y crear personas jurídicas que les sirvan de medio para alcanzar sus fines misionales propios, docencia, investigación y extensión.

La existencia de estas normas estatutarias no es gratuita, e implica que en los parámetros del artículo 69 de la Constitución Nacional y de la Ley 30 de 1992 se encontró suficiente respaldo para asignar a los consejos superiores de las universidades públicas la facultad de autorizar al respectivo ente universitario, mediante el correspondiente acto administrativo, su participación como socio de una empresa de economía mixta.

- La autorización general contenida en el artículo 96 de la Ley 489 de 1998

Según lo planteado en esta norma, todas las entidades públicas, sin importar su "naturaleza y orden administrativo" (por consiguiente incluidas las universidades públicas), están facultadas legalmente para celebrar convenios de asociación, y lo que es más relevante, para la creación de personas jurídicas, todo esto bajo el entendido de que dichas facultades serán ejercitadas en cumplimiento de los principios de la función administrativa, y en ejecución de actividades relacionadas con sus fines misionales.

- El hecho de que las leyes de autorización para la creación de sociedades de economía mixta solo lo son en sentido formal, y en algunos casos consisten en actos administrativos

Tal como se explicó en este trabajo, la denominada ley de autorización, que hace parte del complejo proceso para la constitución de una sociedad de economía mixta, no cumple con los requisitos y características necesarios para que sea considerada una ley en sentido material, ya que no se trata de una disposición de carácter general y abstracto, sino de un acto de contenido singular y concreto, por lo que únicamente en 
algunos casos, cuando la expide el Congreso de la República, y solo por su origen, alcanza la denominación de "ley" en sentido formal.

En los demás casos, tratándose de autorizaciones dadas por las asambleas departamentales y los concejos municipales, dicha autorización se materializa a través de un acto administrativo común y corriente, razón que nos lleva a concluir que en el caso de las universidades públicas se podría realizar por medio de un acuerdo del consejo superior universitario (acto administrativo), debidamente facultado para ello dentro de los estatutos generales correspondientes.

Se trata en este caso de un acto administrativo constitutivo, de acuerdo con la clasificación propuesta por PAREJO ALFONSO:

"los actos pueden ser constitutivos, cuando crean, modifican o extinguen relaciones o situaciones jurídicas (por ejemplo el otorgamiento de una concesión, una orden de derribo de un edificio, el nombramiento de un funcionario, etc.), y declarativos, cuando se limitan a acreditar tales relaciones o situaciones $\sin$ alterarlas" (PAREJO ALFONSO, 2001).

- La conclusión de que las sociedades de economía mixta no son exclusivas de la rama ejecutiva

Otra importante conclusión que sirve de soporte para cimentar la teoría de las universidades públicas como entes constituyentes de sociedades de economía mixta es que, a pesar de algunas posiciones doctrinales, no existe norma constitucional o legal que disponga de manera perentoria y restrictiva que estas sociedades sean de pertenencia exclusiva de la rama ejecutiva del poder público.

Partiendo de la certeza de esta afirmación, y apoyados en el pronunciamiento de la Corte Constitucional en sentencia C-629 de 2003, con ponencia del magistrado ÁLVARO TAFUR GALVIS, que concluyó que se trata de sociedades cuya constitución sea del resorte exclusivo del ejecutivo, nada obsta para concluir que una entidad autónoma universitaria puede perfectamente proceder a la constitución de una de ellas.

- Lo previsto en el Decreto 393 de 1991 en relación con actividades científicas y tecnológicas

Siendo las universidades centros del saber, y prototipos de lo que en estricto sentido se puede considerar como un ente de naturaleza científica, consideramos importante anotar que el Decreto 393 de 1991 habilita a las entidades públicas que desarrollen este tipo de actividades para que constituyan sociedades de economía mixta, entre otras formas de asociación.

"Como se aprecia de su lectura, la ley especial prevé dos formas de asociación que tienen las entidades públicas con los particulares para la realización de las actividades de ciencia y tecnología: la creación de 
nuevas personas jurídicas, y la simple asociación convencional mediante acuerdos de cooperación. Cabe mencionar la correspondencia que existe entre las reglas transcritas y la ley 489 de 1998. Que autoriza a las entidades públicas para asociarse con los particulares bajo las mismas modalidades, con el fin de desarrollar en forma conjunta 'actividades en relación con los cometidos y funciones que les asigna a aquellas la ley" (Consejo de Estado, Sala de Consulta y Servicio Civil, C.P.: EnRIQue José Arboleda Perdomo, 8 de julio de 2010, rad. 11001-03-06-0002010-00058-00(2007)).

\section{BIBLIOGRAFÍA}

Ariño OrtiZ, G. (2008). Principios de Derecho Público Económico. Bogotá: Universidad Externado de Colombia.

BRewer-Carías A. (2005). Derecho administrativo. Boogtá: Universidad Externado de Colombia, t. II.

Correa, M. (2008). Libertad de empresa en el Estado social de derecho. Bogotá: Universidad Externado de Colombia.

Garrigues, J. (1987). Curso de Derecho Mercantil, t. II. Bogotá: Temis.

Gordillo, A. (s. f.). Tratado de Derecho Administrativo, t. I, 8. ${ }^{a}$ ed. Buenos Aires: Fundación de Derecho Administrativo.

Montaña Plata, A. (2010). Fundamentos de Derecho Administrativo. Bogotá: Universidad Externado de Colombia.

Narváez García, J. (2002). Derecho Mercantil Colombiano. Tipos de Sociedad, t. IV, 2. ${ }^{a}$ ed. Bogotá: Legis.

Narváez García, J. I. (2002). Derecho Mercantil Colombiano. Teoría General de las Sociedades. 9. ${ }^{a}$ ed. Bogotá: Legis.

Parejo Alfonso, L. (2001). Lecciones de Derecho Administrativo. 3. ${ }^{a}$ ed. Bogotá: Universidad Externado de Colombia.

Pérez Escobar, J. (1997). Derecho Constitucional Colombiano. 5. a ed. Bogotá: Temis.

Reyes Villamizar, F. (s. f.). Derecho Societario, t. I, 2. ${ }^{a}$ ed. Bogotá: Temis.

Robledo Silva, P. (2010). La autonomía municipal en Colombia. Bogotá: Universidad Externado de Colombia. 
Santofimio Gamboa, J. (2003). Tratado de derecho administrativo. Introducción a los conceptos de la Administración Pública y el derecho administrativo. 3. ${ }^{a}$ ed. Bogotá: Universidad Externado de Colombia.

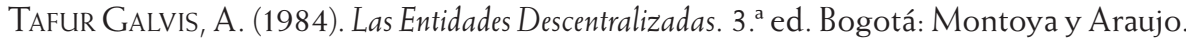

Vidal Perdomo, J. (1987). Derecho Administrativo. 9. a ed. Bogotá: Temis.

Younes Moreno, D. (2014). Curso de Derecho Administrativo. 9. a ed. Bogotá: Temis.

JURISPRUDENCIA NACIONAL

Constitución Política de Colombia.

Consejo de Estado, Sala de Consulta y Servicio Civil, C.P.: EnRIQue José ArboleDA Perdomo, 8 de julio de 2010, rad. 11001-03-06-000-2010-00058-00(2007).

Corte Constitucional, sentencia C-629 de 2003, M.P.: Álvaro Tafur Galvis, exp. D-4448.

Corte Constitucional, sentencia C-220 de 1997, M.P.: FABIO Morón DíAZ.

Corte Constitucional, sentencia C-829 de 2002, M.P.: Alfredo Beltrán Sierra. 